\title{
Avaliação na conformação de vertente em face das propriedades físicas da cobertura pedológica na área experimental do Departamento de Solos/Campus da Universidade Federal de Santa Maria
}

\author{
Evaluation on the hill slope conformation face physical properties of the pedological \\ cover in the Soil Departament experimental area in the Campus of the Federal \\ University of Santa Maria
}

\author{
Mauro Kumpfer Werlang ${ }^{1}$, Arthur Piccolo Werlang ${ }^{2}$, Rômulo Aragonês Aita ${ }^{1}$, Ivete Rodrigues ${ }^{1}$ \\ ${ }^{1}$ Universidade Federal de Santa Maria, Santa Maria, RS Brasil \\ wermakwer@gmail.com; romuloaita@gmail.com \\ ${ }^{2}$ Secretaria de Planejamento Prefeitura Municipal de Gramado, RS Brasil \\ werlang.a@gmail.com; iveterodrigues85@gmail.com
}

\begin{abstract}
Resumo
Entender o processo de formação dos solos e sua distribuição na superfície terrestre permite estudar processos, o sentido e a evolução da pedogênese. Esses estudos possibilitam a compreensão de mecanismos responsáveis pelas diferenciações morfológicas em vertentes. A cobertura pedológica é um sistema estrutural que apreende transformações progressivas das organizações, tanto vertical quanto lateralmente no sentido da vertente, estando relacionada com os outros elementos da paisagem, especialmente o relevo. O objetivo foi avaliar as propriedades físicas da cobertura pedológica para entender sua dinâmica de evolução examinando a influência na morfogênese da vertente. Foram determinadas propriedades físicas da cobertura pedológica e investigado o comportamento morfogenético da vertente. Considerou-se a característica da cobertura pedológica quanto à distribuição do tamanho de partículas, limites de consistência, densidade aparente, índice de vazios, grau de compacidade e porosidade total. Adotou-se o método dedutivo, acreditando-se ser esta uma das formas que melhor permite uma proximidade da realidade com a pesquisa. O resultado evidenciou a relação solo-paisagem ratificando a concepção de que a morfogênese da vertente está condicionada pelas propriedades da cobertura pedológica e, que a vertente evolui da influência exercida por essas propriedades. Concluiu-se que a cobertura pedológica condiciona a conformação do perfil da vertente estudada.

Palavras-chave: Vertente; Evolução morfogenética; Relação solo-paisagem
\end{abstract}

\begin{abstract}
Understanding the process of soil formation and its distribution on the Earth surface allow us to study the biogeodynamics process, the meaning and the evolution of pedogenesis. Such studies, lead to the understanding of mechanisms responsible for the hillslope morphological differences. The pedological cover is a structural system that holds the progressive transformation of its structures, both vertically and laterally down the hillslope being closely related to other landscape elements, especially the relief. This piece of work was aimed to evaluate the hillslope conformation face to physical and dynamic proprieties found in a hillslope pedological cover section with the purpose of understanding its evolution dynamics and examining the influence of such proprieties on hillslope morphogenesis. The study took place in the Soil Departament experimental area in the Campus of the Federal University of Santa Maria where the physical proprieties of pedological cover were determined and the behavior of such proprieties examined in the hillslope morphogenesis. In this case, the grain particle size distribution, Atterberg limits, bulk density, ratio void, compactness degree and total porosity were considered. The deductive method was used, considering this the best approach that most closely approximates research to reality. The result has shown the soil-landscape relationship, ratifying the conception that the hillslope morphogenesis is conditioned by the properties of the pedological cover and that the hillslope evolves from the influence exerted by those properties. Therefore, it is concluded that the pedological cover conditions the conformation of the hillslope profile studied.
\end{abstract}

Keywords: Hillslope; Morphogenetic evolution; Soil-landscape relationship 


\section{Introdução}

As vertentes, juntamente com os interflúvios e os talvegues, são reconhecidas sendo as componentes fundamentais das unidades de relevo. Por relevo entende-se como a diversidade de formas da superfície da crosta terrestre. Ao se considerar que o relevo terrestre evolui surgem questões de como e de que maneira se processa o desenvolvimento das formas, quais as condições iniciais e até que fase se processa a evolução. Nesse raciocínio, torna-se, portanto, evidente a importância do conhecimento relativo à morfogênese de vertentes a partir do controle do exercido pela cobertura pedológica.

Os primeiros avanços referentes à evolução na compreensão da organização do solo e as metodologias para seu estudo datam de 1930. É nessa década que Milne apresenta o conceito de catena e introduz a concepção de lateralidade do solo, onde os perfis verticais de solo sucedem-se numa vertente, ligados como que em cadeia, sendo que os principais fatores responsáveis pelas sucessões de solos numa encosta seriam os processos erosivos, comandados pela topografia. Na década de 60 ocorreu outro importante avanço: a introdução da noção de tridimensionalidade, onde cada unidade representada por horizontes verticalmente dispostos ocuparia um determinado volume no espaço. Entretanto, mantém-se a concepção de que o espaço pedológico seria constituído pela justaposição de perfis verticais de solo (Queiroz Neto, 1988). Na década seguinte, foram realizados importantes trabalhos, os quais passaram a introduzir uma nova metodologia de análise através da concepção de cobertura pedológica (Queiroz Neto 1988; 2000). Assim, trabalhos como os de Bouquier (1971), Boulet (1974) e Chauvel (1977), estão citados por Queiroz Neto (2000) enfatizando o estudo de topossequências ao longo de encostas realizando análises bidimensionais das coberturas pedológicas, não mais destacando o solo como um indivíduo em perfis verticais, mas sim como um continuum recobrindo toda a extensão das encostas.

Ainda na década de 70, Boulet (1978) e Boulet et al (1979) propõem o estudo e a representação cartográfica tridimensionais da cobertura pedológica, permitindo assim conforme Queiroz Neto (1988) estudar os processos biogeodinâmicos, o sentido e a evolução da pedogênese; reconstituir os diferentes mecanismos responsáveis pelas diferenciações pedológicas, bem como suas sucessões cronológicas; demonstrando assim o comportamento e funcionamento atual da cobertura pedológica de uma dada área.

A partir das pesquisas realizadas pelos pedólogos franceses, pode-se perceber que a cobertura pedológica é um sistema estrutural complexo que apresenta transformações progressivas das organizações, tanto vertical quanto lateralmente no sentido da vertente estando intimamente relacionado com os outros elementos da paisagem, especialmente o relevo.

No Brasil, a proposta metodológica de análise estru- tural da cobertura pedológica passou a ser empregada no final da década de 70, com o intuito de identificar diferentes sucessões de perfis de solos ao longo de encostas, compreender a gênese e evolução dos solos e das paisagens e ainda "explicar a distribuição dos solos como conseqüência de processos pedogenéticos e morfogenéticos complexos" (Queiroz Neto, 1988, p. 416).

O trabalho foi desenvolvido em uma área onde evolui relevo de dissecação e do pressuposto de que ele se desenvolve associado à natureza do material sedimentar que compõe a vertente (areia fina, silte, argilas de baixa a média plasticidade, argilas arenosas e argilas siltosas), o que confere influência às propriedades físicas e dinâmicas para a cobertura pedológica. Também se considerou que a relação entre a configuração da vertente (grau de entalhamento do talvegue e dimensão interfluvial) e do modelado do relevo (dissecação) permite estabelecer uma relação de causa e efeito, refletida na forma ou os conjuntos de formas, a partir do comportamento das características da cobertura pedológica. Nesta perspectiva, o presente trabalho tem por objetivo geral caracterizar a cobertura pedológica ao longo de uma seção de vertente a fim de entender sua dinâmica de evolução face às propriedades físicas e dinâmicas da cobertura pedológica avaliando a influência dessas propriedades na morfogênese da vertente. A figura 1 ilustra a localização da vertente estudada em relação ao município de Santa Maria, RS.

\section{Material e métodos}

\section{Descrição geral da área}

O município de Santa Maria, no que se refere ao relevo, reflete a condição da sua posição situada numa área de transição geomorfológica entre os Planaltos e Chapadas da Bacia Sedimentar do Paraná e a Depressão Periférica Sul-riograndense. As atuações dos agentes erosivos morfogenéticos definiram as formas de relevo e estão associados à diversidade litoestrutural da área abrangida pelo município.

No contexto, da região central do estado do Rio Grande do Sul e da Depressão Periférica Sul-riograndense, é que está situada a área de estudo junto ao Campus da Universidade Federal de Santa Maria, no município de Santa Maria, região central do estado do Rio Grande do Sul. A área foi durante muitos anos utilizada para o plantio de cultivos convencionais e, ainda hoje apresenta uso da terra com lavoura temporária em rotação com pousio. Apresenta aspectos da biota regional inserida no domínio dos Campos com Capões e Matas Galerias (Vieira, 1984). Nos setores onde os processos erosivos esculpiram colinas alongadas (coxilhas) sobre litologias paleozóicas da Bacia do Paraná, aparecem solos medianamente profundos como os Argissolos. Nas áreas 


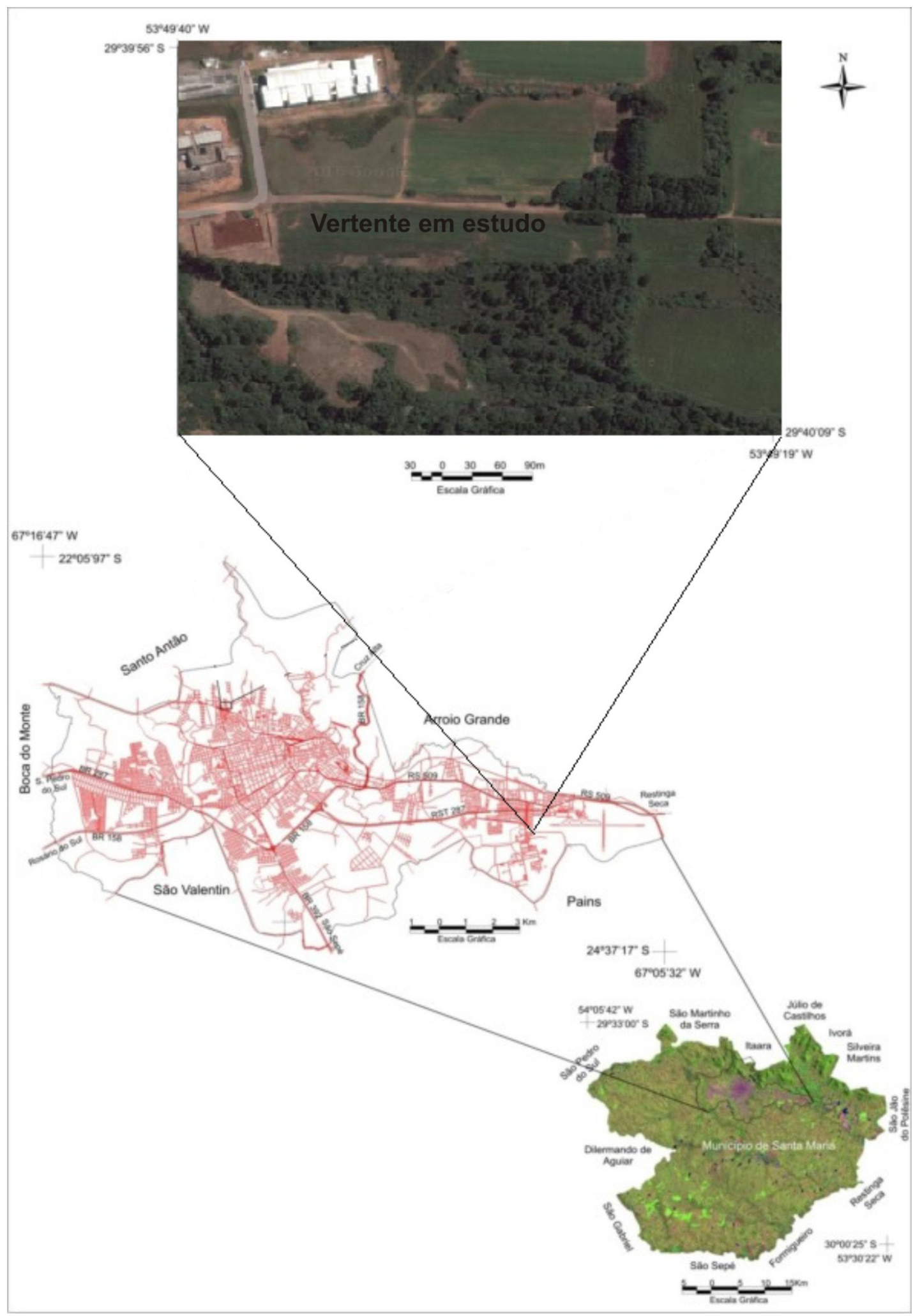

Figura 1 - Localização da vertente estudada em relação ao município de Santa Maria, RS Fonte do fragmento da imagem: Adaptado de Google Maps (2016)

Organização dos autores 
aluvionais ocorrem Planossolos e Gleissolos. No que se refere ao clima, de acordo com a classificação de Köppen apud Ayoade (1986), a região apresenta domínio climático do tipo Cfa, ou seja, temperado chuvoso e quente, onde se registram temperaturas entre $-3^{\circ} \mathrm{C}$ e $18^{\circ} \mathrm{C}$ nos meses mais frios e nos meses mais quentes temperaturas superiores a $22^{\circ} \mathrm{C}$, sem nenhuma estação seca.

\section{Procedimentos operacionais}

A orientação metodológica esteve baseada na adoção da proposição da análise sistêmica da paisagem (Sochava, 1972; Bertrand, 1968, 1971; Monteiro, 2000) e dos níveis de tratamento definidos por Ab'Saber (1969). Classificados em grupos epistemológicos os métodos podem ser indutivos, dedutivos, hipotético-dedutivo, dialético e, fenomelógico.

Para realização do trabalho, fez-se uso do método dedutivo, acreditando-se ser esta uma das formas que permite uma maior proximidade da realidade com a pesquisa. De acordo com os objetivos do trabalho, adotou-se como base teórico-metodológica a proposta de Boulet apud Queiroz Neto (1988), que trata da análise estrutural da cobertura pedológica, buscando-se assim, a compreensão da bidimensionalidade da dinâmica da cobertura pedológica e a relação com os outros elementos da paisagem.

A partir da topossequência de vertente selecionada foi descrito o perfil do solo no terço superior da vertente. Nesse perfil foram identificados cinco horizontes diagnósticos. Desses horizontes foram coletadas amostras de solo deformadas e indeformadas. As coletas das amostras foram feitas sob condições atmosféricas de tempo bom e com o solo apresentando condições de umidade que permitissem a coleta de amostras indeformadas. Os ensaios foram realizados no laboratório de sedimentologia do Departamento de Geociências da Universidade Federal de Santa Maria. Os parâmetros físicos determinados foram a distribuição do tamanho de partículas (análise granulométrica), diâmetro efetivo (D10, D30 , D60 ), Coeficiente de Curvatura (Cc), Coeficiente de Uniformidade $(\mathrm{Cu})$ densidade de partículas $(\gamma s)$, densidade aparente $(\gamma d)$, índice de vazios $(\mathrm{e})$, índice de vazios máximo (e máx), índice de vazios mínimo (e min), grau de compacidade (GC), porosidade total (N). Foram também determinados (NBR 6459/84) os limites de consistência: limite de Contração (LC), limite de plasticidade (LP), limite de liquidez (LL) além do índice de plasticidade (IP). Também foram realizados ensaios de resistência à penetração em três pontos da topossequência da vertente sob as mesmas condições de campo. A resistência à penetração foi medida com o penetrômetro de percussão Modelo Stolf, cuja altura de queda do cilindro de peso constante utilizada foi a marca de $40 \mathrm{~cm}$ de queda. A figura 2 mostra a trincheira ilustrando o perfil do solo no terço superior da vertente estudada.

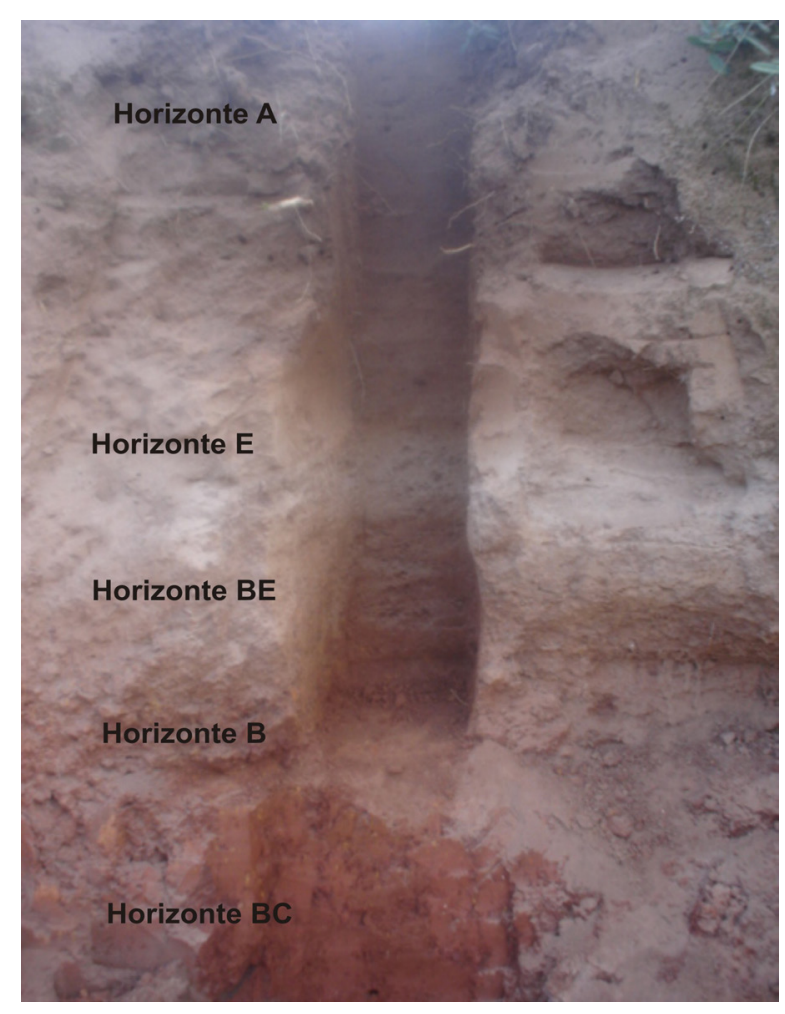

Figura 2 - Aspecto da trincheira e da disposição dos horizontes do perfil do solo no terço superior da vertente em estudo

Fonte: Trabalho de campo em outubro 2015

As amostras deformadas foram coletadas, etiquetadas e armazenadas em saco plástico com 500g e conduzidas ao laboratório com $500 \mathrm{~g}$ em cada um dos horizontes diagnósticos descritos, para a determinação do tamanho de partículas e os limites de consistência. Além dessas, foram coletadas nos mesmos pontos, amostras indeformadas (foram coletadas em anéis de ferro galvanizado com volume e peso conhecido) para a determinação da densidade aparente $(\gamma d)$. Para a determinação do tamanho de partículas da fração areia, utilizou-se o processo por peneiramento e para as partículas da fração silte e argila, a sedimentação, conforme NBR 7181/84. A partir da curva granulométrica foram obtidos o diâmetro efetivo $\mathrm{D}_{10}, \mathrm{D}_{30}, \mathrm{D}_{60}$ e obtidos o Coeficiente de Curvatura (Cc) e Coeficiente de Uniformidade $(\mathrm{Cu})$. O índice de vazios (e), índice de vazios máximo (e máx), índice de vazios mínimo (e min), grau de compacidade (GC) e a porosidade (n) foram obtidos através da aplicação de equações.

O grau de compacidade (GC) foi determinado através da expressão (Vargas,1977; Caputo,1988; Holtz; Kovacs,1981):

Onde: $G=$ grau de compacidade; emáx = índice

$$
\boldsymbol{G}=\frac{e m a ́ x-e n a t}{e m a ́ x-e \min }
$$

de vazios máximo; $e$ min = índice de vazios mínimo; enat $=$ densidade do solo $(\gamma d)$. 
A densidade aparente do solo ( $\gamma d$ ) foi obtida pela expressão:

$$
y d=\frac{w s}{v}
$$

Onde: $\gamma d=$ densidade aparente do solo, $\mathrm{gcm}^{3} w s=$ massa dos sólidos seca, $\mathrm{gcm}^{-3} \mathrm{e}^{v=}$ volume total da amostra, $\mathrm{g} \mathrm{cm}^{-3}$

A densidade de partículas do solo (ys) foi obtida pela expressão:

$$
y s=\frac{w s}{v}
$$

Onde: $y s=$ densidade de partículas do solo, $\mathrm{gcm}^{-3}$ ; $w s=$ massa das partículas, $\mathrm{gcm}^{-3}$ e $v=$ volume das partículas, $\mathrm{gcm}^{-3}$.

A determinação do índice de vazios máximo e índice de vazios mínimo foram dados pelas expressões:

$$
\begin{gathered}
\text { emáx }=\frac{y_{s}}{y_{s} \min }-1 \\
e \min =\left(y_{s} / y_{s m a ́ x}\right)-1
\end{gathered}
$$

Onde: $y s=$ densidade da amostra do solo determinada de acordo com a ABNT-NBR 6508/80, em $\mathrm{gcm}^{-3}$; ys min = densidade do solo seco mínima do solo, em $\mathrm{gcm}^{-3} ;$ ysmáx $=$ densidade do solo seco máxima da amostra de solo, em $\mathrm{gcm}^{-3}$.

O índice de vazios foi obtido pela expressão:

Onde: $e=$ índice de vazios e $n=$ porosidade total

$$
e=\frac{n}{(1-n)}
$$

dada pela expressão:

Onde: $y s=$ densidade da amostra do solo determi-

$$
\left(1-\left(\frac{\gamma s}{\gamma d}\right)\right.
$$

nada de acordo com a ABNT-NBR 6508/80, $\mathrm{em} \mathrm{gcm}^{-3} \mathrm{e}$ $y d=$ densidade aparente do solo, $\mathrm{gcm}^{-3}$.

O Coeficiente de Curvatuta (Cc) e Coeficiente de Uniformidade $(\mathrm{Cu})$ foram obtidos pela expressão (Caputo, 1988):

$$
\begin{aligned}
& C u=\frac{D_{60}}{D_{10}} \\
& C c=\frac{\left(D_{30}\right)^{2}}{\left(D_{60} \cdot D_{10}\right)}
\end{aligned}
$$

Onde: $\mathrm{Cu}=$ Coeficiente de Uniformidade (adimensional); $\mathrm{C} c=$ Coeficiente de Curvatura (adimensional); D60=Diâmetro das peneiras que permitem passar $60 \%$ da areia $(\mathrm{mm}) ; \mathrm{D} 30=$ Diâmetro das peneiras que permitem passar 30\% da areia $(\mathrm{mm})$; D10=Diâmetro das peneiras que permitem passar $10 \%$ da areia $(\mathrm{mm})$.

\section{Resultados e discussão}

O relevo constitui a diversidade de formas da superfície terrestre. É, portanto, o resultado da atuação de processos naturais e, em alguma medida também, antropogênicas, que ocorrem na superfície terrestre. Caracteriza-se pelo conjunto de superfícies geomórficas. Ao considerar que a evolução morfogenética de vertentes apresenta estreita relação com o fluxo superficial e subsuperficial da água, a evolução do perfil e da forma da vertente traduz a atuação dos morfogenéticos que atuam na vertente. $\mathrm{O}$ movimento de água contribui com esses processos através do transporte de materiais das partes mais elevadas para as mais baixas (processos de degradação e agradação) que acontecem em superfície e internamente ao longo da vertente. A diversidade de formas ao longo da vertente dá-se nos diferentes segmentos de vertentes resultando em perfis côncavos, convexos, retilíneos, côncavos-convexos, convexos-côncavos.

O quadro 1 traz o resultado da descrição morfológica do perfil de solo no terço superior da vertente estudada. Quadro1: descrição morfológica do perfil de solo no terço superior da vertente estudada.A vertente estudada apresenta desde o topo em direção à base, forma convexo-côncavo-côncava, ou seja, passa de uma forma convexa na porção superior para convexa no segmento inferior próximo da base. Isso evidencia que a maior perda por denudação aconteceu no segmento médio e inferior da vertente.

A figura 3 ilustra a conformação da forma da vertente em estudo. Observa-se que o perfil evolui de uma forma convexa para côncava, apresentando um ponto de inflexão no terço médio.

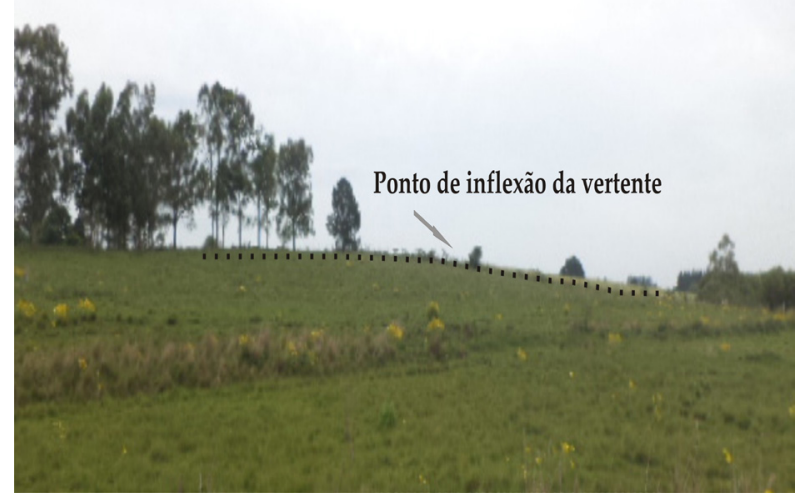

Figura 3 - Aspecto da conformação da forma da vertente em estudo Fonte: Trabalho de campo em outubro 2015 
Quadro1- descrição morfológica do perfil de solo no terço superior da vertente estudada

LOCALIZAÇÃO: Estrada de acesso ao campo de experimentos Centro de Ciências Rurais da Universidade Federal de Santa Maria - UFSM, Santa Maria-RS, Bairro Camobi (UFSM), a aproximadamente 200 metros nos fundos do Hospital Universitário de Santa Maria.

ALTITUDE: $105 \mathrm{~m}$

FORMAÇÃO GEOLÓGICA: Formação Santa Maria (Membro Alemoa).

MATERIAL ORIGINÁRIO: Arenitos finos, lamitos, argilitos e folhelhos sílticos-argilosos.

RELEVO LOCAL: Suave ondulado

RELEVO REGIONAL: Suave ondulado

EROSÃO: Entressulcos (laminar ligeira)

CLIMA: Cfa (mesotérmico brando na classificação de Köppen), Udic e Thermic.

DRENAGEM: Bem drenado

VEGETAÇÃO: Campos com capões e matas ciliares.

USO ATUAL: Lavoura temporária.

DESCRITO E COLETADO: pelos autores.

Horizonte A: 0-44 cm; (5 YR 2,5/2, úmido); franco-arenosa; fraca, blocos angulares; poros pequenos e comuns; friável, não plástica e ligeiramente pegajosa; transição gradual; raízes abundantes.

Horizonte E: 44-75 cm (7,5 YR 4/4, úmido); franco-arenosa; fraca, blocos angulares, poros muitos e pequenos; muito friável; não plástica e ligeiramente pegajosa; transição gradual; raízes comuns.

Horizonte BE: 75-103 cm; (5 YR 4/6, úmido); franco-argilo-arenosa; moderada, blocos angulares; poros muitos e pequenos; friável, ligeiramente plástica e ligeiramente pegajosa; transição difusa; poucas raízes.

Horizonte B: 103-143 cm; (2,5 YR 4/6, úmido); argilosa; fraca a moderada, blocos angulares; poros pequenos e comuns; firme, ligeiramente plástica e ligeiramente pegajosa; transição difusa; poucas raízes.

Horizonte BC: 143 + cm; (2,5 YR 4/8, úmido); argilo-arenosa; fraca, blocos angulares; poros pequenos comuns; firme, ligeiramente plástica e ligeiramente pegajosa; transição difusa, poucas raízes.

Observações: Presença de mosqueados de cor vermelha (10 R 4/8, úmido), poucos, pequenos a médios no horizonte $\mathrm{BC}$.

Na Tabela 1 tem-se a distribuição do tamanho das partículas do solo no terço superior da vertente estudada. Esse ensaio de determinação auxilia na compreensão da organização física do solo que contribui para o resultado das propriedades dinâmicas. Nota-se nos resultados da Tabela 1, que os horizontes A, E e BC caracterizam-se por apresentar uma grande quantidade de areias. Os horizontes BE, B e BC apresentam grande quantidade partículas na fração tamanho argila, caracterizando uma translocação das argilas dos horizontes diagnósticos superficiais para os subsuperficiais.

Na Tabela 2 têm-se os parâmetros físicos, na Tabela 3 os limites de consistência e na Tabela 4 o diâmetro efetivo D10, D30, D60, o coeficiente de curvatura e o coeficiente de uniformidade.

Os resultados indicam um incremento no teor de argila 
Tabela 1 - Distribuição do tamanho de partículas do perfil de solo no terço superior da vertente estudada

\begin{tabular}{|c|c|c|c|c|}
\hline \multicolumn{5}{|c|}{ Composição granulométrica da terra fina (dispersã } \\
\hline & Profundidade & Areia & Silte & Argila \\
\hline & $(\mathrm{cm})$ & $(2-0,06 \mathrm{~mm})$ & $(0,05-0,002 \mathrm{~mm})$ & $(<0,002 \mathrm{~mm})$ \\
\hline $\mathrm{A}$ & $0-44$ & 53,53 & 32,33 & 14,14 \\
\hline $\mathrm{E}$ & $44-75$ & 49,01 & 49,17 & 0,36 \\
\hline $\mathrm{BE}$ & $75-103$ & 33,96 & 25,47 & 40,57 \\
\hline B & $103-143$ & 29,23 & 29,81 & 40,90 \\
\hline $\mathrm{BC}$ & $143+$ & 48,14 & 19,97 & 30,88 \\
\hline
\end{tabular}

Tabela 2 - Parâmetros físicos do perfil de solo no terço superior da vertente estudada

\begin{tabular}{cccccccc}
\hline Horizontes & $\gamma d$ & $\gamma s$ & $\begin{array}{c}\text { e max } \\
(\mathrm{gcm}-3)\end{array}$ & $\begin{array}{c}\text { e min } \\
(\mathrm{gcm}-3)\end{array}$ & $\mathrm{e}$ & $\mathrm{N}$ & $\mathrm{GC} \%$ \\
$\mathrm{Accm}-3)$ & & & & & \\
E & 1,53 & 2,44 & 0,33 & 6,47 & 0,59 & 37,30 & 19,60 \\
BE & 1,68 & 2,61 & 0,36 & 6,34 & 0,56 & 35,82 & 22,06 \\
B & 1,29 & 2,62 & 0,65 & 3,06 & 1,03 & 50,76 & 26,72 \\
BC & 1,21 & 2,65 & 0,75 & 2,53 & 1,19 & 54,34 & 25,81 \\
\hline
\end{tabular}

Tabela 3 - Limites de consistência do perfil de solo no terço superior da vertente estudada

\begin{tabular}{ccccc}
\hline Horizontes & LL & LP & LC & IP \\
\hline A & NP & NP & - & - \\
\hline E & NP & NP & - & 16,35 \\
\hline BE & 33,78 & 17,6 & 24,77 & 16,18 \\
\hline B & 51,61 & 21,3 & 16,02 & 15,10 \\
\hline BC & 38,49 & 21,7 & 16,79 \\
\hline
\end{tabular}

Tabela 4 - Diâmetro efetivo D10, D30, D60, coeficiente de curvatura e coeficiente de uniformidadedo perfil de solo no terço superior da vertente estudada

\begin{tabular}{cccccc}
\hline Horizontes & $\mathrm{D} 10$ & $\mathrm{D} 30$ & $\mathrm{D} 60$ & $\mathrm{Cu}$ & $\mathrm{Cc}$ \\
\hline $\mathrm{A}$ & 0,0006 & 0,030 & 0,100 & 166 & 15 \\
\hline $\mathrm{E}$ & 0,0150 & 0,031 & 0,090 & 6 & 0,71 \\
\hline $\mathrm{BE}$ & 0,0003 & 0,0005 & 0,030 & 100 & 0,02 \\
\hline $\mathrm{B}$ & 0,0003 & 0,0005 & 0,040 & 133 & 0,016 \\
\hline $\mathrm{BC}$ & 0,0004 & 0,0006 & 0,090 & 225 & 0,008 \\
\hline
\end{tabular}

com o aumento da profundidade, exceto o horizonte E que apresenta quase nenhum teor de argila e o horizonte BC que assume características do substrato litológico da Formação Santa Maria, Membro Alemoa.A característica granulométrica encontrada indica a presença de material mal graduado, o que confere a vertente elevado potencial erosivo. A figura 4 ilustra cicatriz decorrente do processo de erosão hídrica que acontece ao longo da superfície da vertente.

Os dados relativos à consistência mostram os horizontes superficiais não plásticos. Os horizontes sub- superficiais apresentam ligeira plasticidade indicando a relação entre a plasticidade e o teor de argila neles presente. Também os horizontes superficias foram os que apresentaram maior densidade aparente e conseqüente menor índice de vazios e porosidade total, indicando maior impacto pela antropização. O maior grau de compacidade apresentado pelos horizontes subsuperficiais estão relacionados a composição granulométrica e ao adensamento que sofreram, tanto pela translocação das argilas quanto pelo uso da terra.

Os resultados indicam que nos horizontes superfi- 


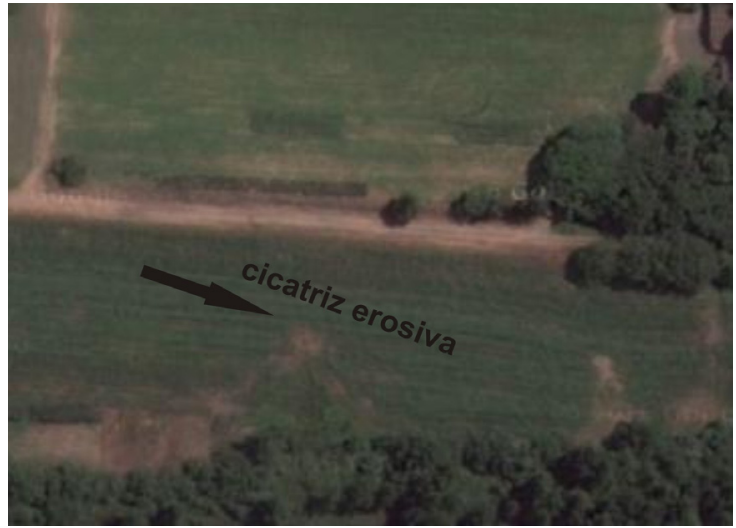

Figura 4 - Aspecto da área abrangida pela vertente em estudo mostrando cicatriz erosiva no terço médio inferior da vertente.

Fonte: Adaptado de Google Maps (2016)

ciais há uma maior facilidade de infiltração da água da chuva e que essa infiltração, no sentido vertical, tende a diminuir quando atinge os horizontes subsuperficiais promovendo o processo de exfiltração lateral ao longo da vertente. Essa condição do comportamento da cobertura pedológica influencia no processo de infiltração/exfiltração da água, refletindo no comportamento morfodinâmico da vertente. A figura 5 ilustra processo de exfiltração lateral que ocorre ao longo da vertente. Esse reflexo pode ser verificado pela inflexão no perfil quando passa de convexo para côncavo. Esse segmento côncavo da vertente estudada apresenta uma menor espessura no perfil do solo. Nele também se observa maior exfiltração da água o que leva a conclusão de que a maior intensidade de denudação acontece nesse segmento da vertente.

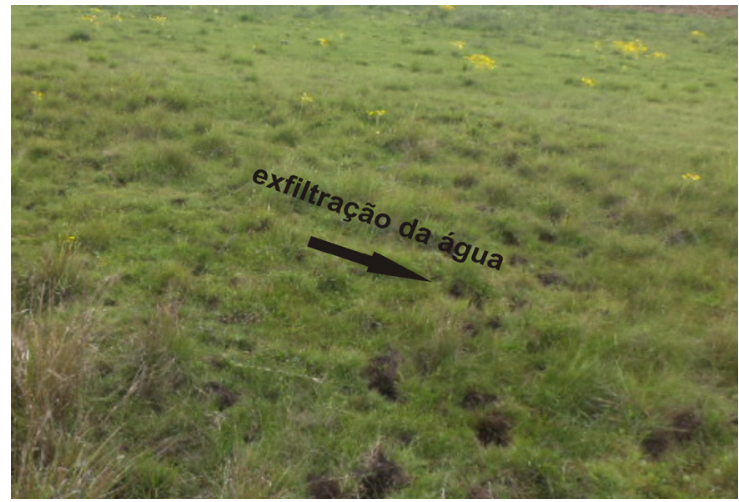

Figura 5 - Processo de exfiltração lateral que ocorre ao longo da vertente. Esse mecanismo de saída d'água pode ser verificado a partir do ponto de inflexão no perfil da vertente quando esse passa de convexo para côncavo.

Fonte: Trabalho de campo em outubro 2015.

Também o resultado obtido indica que o processo de erosão hídrica influenciado pelo mecanismo de infiltra- ção e exfiltração da água, é controlado pela natureza da cobertura pedológica. Esse mecanismo, em subsuperfície, ou seja, nos horizontes subsuperficiais, atua de forma mais incisiva na interface entre o horizonte E, BE e B e BC. Pode-se ainda afirmar que a alternância da convexidade para a concavidade apresentada pelo perfil da vertente está relacionada com a exfiltração da água em face das propriedades apresentadas pelos horizontes do solo. Portanto, as propriedades da cobertura pedológica exercem forte influência na conformação do perfil da vertente estudada.

\section{Conclusões}

Os resultados obtidos indicam que a cobertura pedológica exerce influência na conformação do perfil da vertente. A maior convexidade na porção superior e a maior concavidade na porção inferior da vertente relacionam-se a características da cobertura pedológica. Também é possível concluir que os processos de erosão hídrica atuam de forma mais incisiva na interface entre o volume E com o B, revelando ser este o setor da vertente com maior fragilidade face a atuação de processos erosivos em subsuperfície. Concluiu-se também que a concavidade do segmento inferior da vertente, é em grande parte, controlada pela exfiltração da água que acontece a partir do ponto de inflexão e da característica apresentada pelos horizontes do solo. A conformação da vertente está relacionada aos fluxos subsuperficiais que tendem a exfiltrar na interface do horizonte $\mathrm{E}$ com o B e BC.

O resultado do trabalho evidencia, portanto, a relação solo-paisagem. Além disso, reforça a tese de que a diversidade de formas da superfície terrestre, ou seja, o relevo evolui como resultado da influência exercida pelas propriedades da cobertura pedológica uma vez que elas influenciam o fluxo subsuperficial da água ao longo das vertentes.

\section{Referências}

AB'SABER, A. N. Um conceito de geomorfologia a serviço das pesquisas sobre o Quaternário. Geomorfologia. n.18, IG-USP, São Paulo, 1969.

ABNT - ASSOCIAÇÃO BRASILEIRA DE NORMAS TÉCNICAS. Solo - determinação da distribuição do tamanho de partículas: NBR 7181. Rio de Janeiro, 1984.

ABNT - ASSOCIAÇÃO BRASILEIRA DE NORMAS TÉCNICAS. Solo - determinação do índice de vazios mínimo: NBR 6508/80. Rio de Janeiro, fev. 1991.

AYOADE, J. Introdução à climatologia dos trópicos. São Paulo-SP: Difel, 1986. 
BERTRAND, G. Paysage et géographie physique globale: Esquisse méthodologique.Revue Géographique des Pyrénéeset du Sud-Ovest. Toulouse; 39(3), 249-272, 1968.

BERTRAND, G. Paisagem e geografia física global esboço metodológico. Cadernos de Ciências da Terra. Instituto de Geografia/USP: São Paulo; 1971.

BOULET, R. Toposéquences de sols tropicaux en Haute Volta: équilibres et deséquilibres pédobioclimatiques. Mém. ORSTOM. v.85, 1978.

CAPUTO, H. P. Mecânica dos solos e suas aplicações: Fundamentos. 6. ed, v.1. Rio de Janeiro/RJ: Livros Técnicos e Científicos Editora, 1988.

GOOGLE Maps. Disponível em: https://www.google.com. br/maps/@-29.6939863,-53.7590464,9169m/data=!3m1!1e3 Acesso em: 14 abril 2016.

HOLTZ, R.D.; KOVACS, W.D. An introduction to geotechnical engineering. New Jersey: Prentice-Hael, 1981.

MONTEIRO, C.A.F. Geossistemas: a história de uma procura. São Paulo: Contexto, 2000.

QUEIROZ NETO, J. P. Análise estrutural da cobertura pedológica no Brasil. In: CONGRESSO BRASILEIRO DE CIÊNCIA DO SOLO, 21 Campinas, 1988.

QUEIROZ NETO, J. P. Geomorfologia e pedologia. Revista Brasileira de Geomorfologia. 1:59-67, 2000.

SOTCHAVA, V. B. O estudo de geossistemas. Métodos em Questão. São Paulo; p. 27-36, 1982.

STOLF, R.; FERNANDES, J.; FURLANI NETO, V.L. Penetrômetro de impacto IAA/ PLANALSUCAR-STOLF, recomendação para seu uso. STAB, Piracicaba, n.1, v.3, p.18-23, 1983.

VARGAS, M. Introdução à mecânica dos solos. São Paulo: Mcgraw-Hill do Brasil, 1977.

VIEIRA, E.F. Rio Grande do Sul: geografia física e vegetação. Porto Alegre-RS: Sagra, 1984. 